Original Research Paper

\title{
Selection of Festival Planners: Application of Modified Delphi Method and Analytic Hierarchy Process
}

\author{
${ }^{1}$ Han-Chen Huang, ${ }^{2}$ Su-Ling Wu, ${ }^{3}$ Pei-Ying Wu and ${ }^{4}$ Chien-Hua Li \\ ${ }^{I}$ Department of Tourism and MICE, Chung Hua University, Taiwan \\ ${ }^{2}$ Department of Leisure Management, Yu Da University of Science and Technology, Taiwan \\ ${ }^{3}$ Department of Tourism and MICE, Chung Hua University, Taiwan \\ ${ }^{4}$ Department of Leisure Management, Yu Da University of Science and Technology, Taiwan
}

\section{Article history}

Received: 17-11-2015

Revised: 01-12-2015

Accepted: 09-12-2015

Corresponding Author:

Chien-Hua Li

Department of Leisure

Management, Yu Da University

of Science and Technology,

Taiwan

E-mail: lhualili@yeah.net

\begin{abstract}
There are more than one million festivals regularly held every year around the world. They not only create enormous economic benefits, but have also become a new global industry. Festival activities can attract many visitors and enhance regional development in a short time. The festival is an important trend to develop tourism. In Taiwan and foreign countries, various types of festivals are frequently held to draw the visitors' attention or increase economic benefits. Therefore, the method to hold successful festivals is an important issue for different countries. In order to construct the standard to select festival planners, this study conducts expert interviews and questionnaire survey by literature review and the Modified Delphi Method in order to confirm the hierarchical framework and evaluation criteria. Analytic Hierarchy Process (AHP) is conducted to determine the weights of criteria in the hierarchical framework. The findings can serve as reference to select festival planners, thereby increasing the effectiveness of festivals and helping the decision-making of selection.
\end{abstract}

Keywords: Festivals, Modified Delphi Method, Analytic Hierarchy Process

\section{Introduction}

Since the policy of two-day weekend in Taiwan in 2001, the public has more recreational time and with increased national incomes, the demand for leisure activities also increases. The Taiwan government actively promotes "One Town One Product (OTOP)" policy and encourages local governments to implement economic development, cultural education, create local characteristics, as well as promote festivals (Chen, 2006; Huang, 2015). Festival tourism thus becomes the best option for Taiwan to develop its tourism industry. Shortterm festivals that combine local human resources and cultural assets can enhance the local tourism image and become a main attraction for tourists. In addition, consumption of festival tourism will trigger local economic development (Huang, 2015; Wang, 1999).

"Festival tourism" becomes the best measure for Taiwan to develop its tourism industry (Huang, 2015; Liu et al., 2008). In Taiwan, there are more than 1300 large-scale and small-scale festivals, including more than 600 activities held by local governments and townships.

Festivals are an important trend of tourism development. Taiwan and foreign countries hold various kinds of festivals to attract tourists and increase economic benefits. Thus, how to hold successful festivals is an important issue for different countries.

As the activities are organized by event planners, the selection of appropriate planners determines the effectiveness of activities. Therefore, the research purposes of this study are as follows:

- To construct indicators based on the purposes of activities, for event planner evaluation

- To probe into the weights of indicators to evaluate event planners and establish objective evaluation standards according to the findings

- To provide suggestions on selection of event planners based on the results

The research structure is as shown in Fig. 1. In consideration of research period, manpower and research content, this study treats the related administration personnel in charge of corporate and department activities as subjects. Data are collected from literature review. In addition, due to environmental limitations, this study focuses on experts and scholars in Taipei, Hsinchu and Miaoli of Taiwan and does not conduct national expert interviews. This is the limitation of this study. 


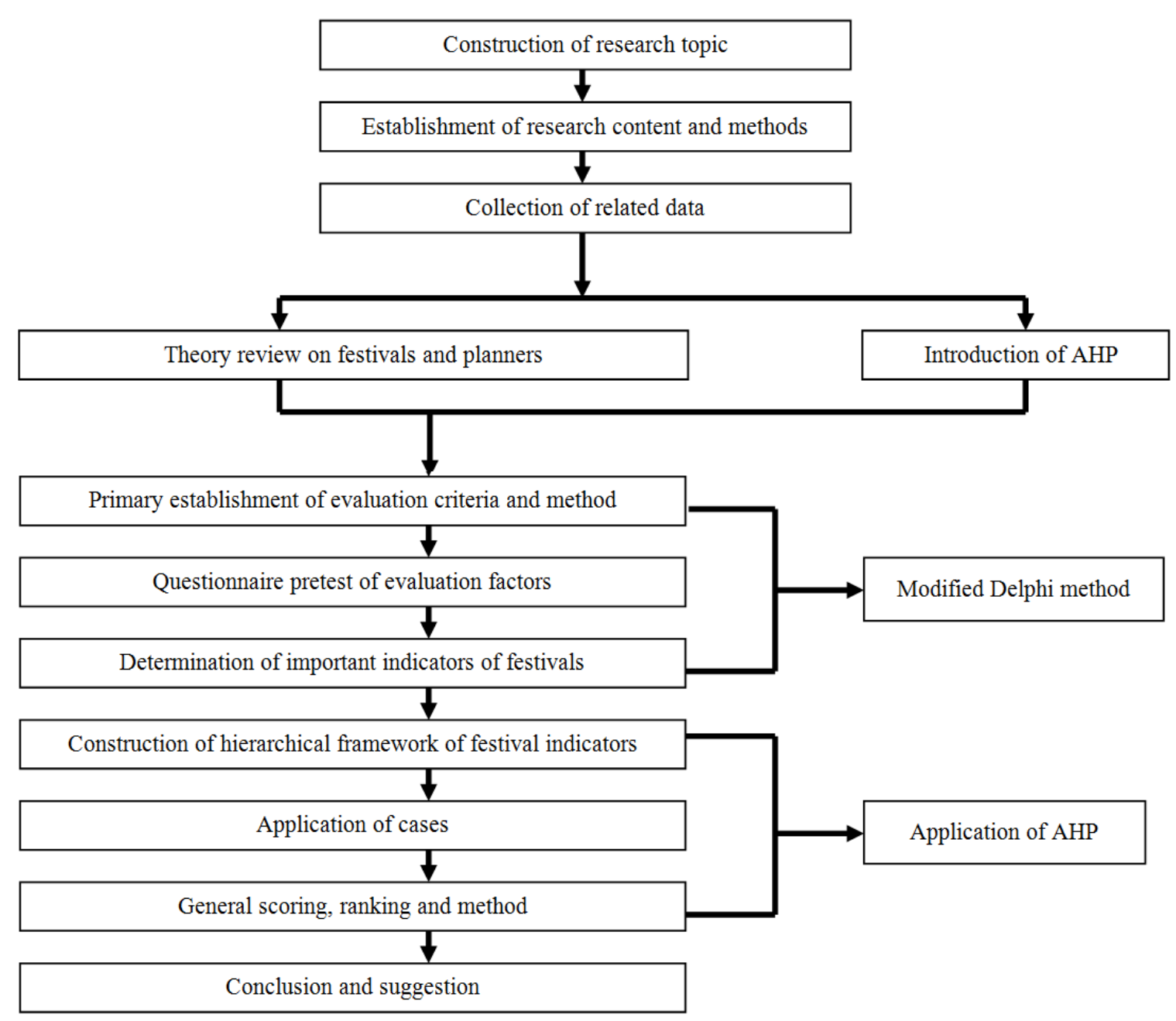

Fig. 1. Research flow

\section{Literature Review}

\section{Concept and Definition of Festivals}

Festivals are unique ceremonies, exhibitions, performances, or celebrations with consciousness and goals to demonstrate special social or cultural issues. Festivals are new and alternative tourism activity models and have become important tourism marketing tools (Lee et al., 2008). Festivals mean special rituals, performances, or celebrations that include planning of special situations to accomplish specific social, cultural, or organizational goals. Festivals are potential measures to deal with urban image problems (Quinn, 2003). Festivals celebrate and remember specific events and are unique celebrations held at specific times and in specific places. The content of festivals include traditional folk customs, religion, aboriginal celebrations, culture and art, sales of agricultural goods, appreciation of natural resources, sports games and local characteristics (Liu and Shih, 2009).
In Taiwan, new local festivals can be divided into three types: (1) artistic and cultural festivals: They are cultural festivals and artistic performances to develop tourism and they are international and demonstrate exchange between eastern and western culture; (2) festivals of industrial promotion and community construction: These festivals promote local industry, show the cultural features of local characteristics and combine total community construction as new festivals; (3) innovative folk festivals: Innovation of traditional festivals with new meanings and new concepts (Huang, 2003). Types of festivals in Taiwan include traditional folk festivals, new cultural festivals, festivals of local industry, large-scale exhibitions, large-scale sports meets and other specific activities (e.g., food shows of Taiwan and international travel fairs) (Cheng and Liu, 2006).

\section{Supplier Selection Criteria}

Research on information service selection suggested that supplier selection criteria include price, cost, quality, 
delivery date, flexibility, production, technique, innovation, service, finance, performance, management, organizational culture, labor-capital relationship, training, inventory, material management and business relationship (Hsiao, 2005).

According to different types of activities, appropriate supplier selection criteria are established and buyers can immediately select qualified suppliers by criteria.

When selecting suppliers, there are different strategic plans for different needs. Experts and scholars propose different research methods, such as the Matrix Model, decision tree-based method, Monte Carlo Simulation, Mathematical Programming, AHP, linear programming, fuzzy synthetic decision approach and the multi-objective decision-making method (Chang, 2009).

\section{Concept of Modified Delphi Method}

The Delphi Method is also known as the Delphi technique (Chang, 2012) and is a kind of group decisionmaking technique. It focuses on future possible events or problems, adopts experts' knowledge and imagination and accomplishes common consensus by specific questionnaire survey. This method effectively allows experts to deal with complicated issues to evaluate current situations, plan for the future, enhance policy quality and diagnose business transformation.

In the first-round of the traditional Delphi Method, by open-ended questionnaire, this study collects experts' opinions to design the second and third rounds of the questionnaire (Huang, 1996). However, in practice of the traditional Delphi Method, due to several rounds of questionnaire, this type of study requires time and it tends to lower the return rate of questionnaires. Therefore, Murry and Hammons (1995) proposed the Modified Delphi Method, which develops the structural questionnaire through literature review and expert indepth interviews to replace the first-round open-ended questionnaire survey.

\section{Concept of $A H P$}

AHP is applied to decision-making problems with uncertainty and multi-criteria (Teng and Tzeng, 1989; Ma et al., 2014; Chang, 2013; Aljuaid et al., 2010). Construction of the relative weight system of capacity indicators by AHP contributes to a combination of professional concepts, knowledge and mathematical and scientific statistics analysis. AHP can reorganize the pairwise comparison matrix and eigen vector to determine the relative weights of factors and repeat confirmation to enhance questionnaire reliability.

\section{Steps}

AHP steps are shown, as follows (Saaty, 1990).

\section{Construction of Pairwise Comparison Matrix}

It is assumed that at a certain level, there are factors $A_{1}, A_{2}, A_{3}, A_{4}, \ldots \ldots, A_{n}$ and weights of the factors are $W_{1}$, $W_{2}, W_{3}, \ldots \ldots, W_{n}$ to establish the pairwise comparison matrix. The relative importance of pair $A_{i}$ and $A_{j}$ is shown by $a_{i j}$. Regarding factor $W_{n}$, the pairwise comparison matrix of $A_{1}, A_{2}, A_{3}, A_{4}, \ldots \ldots A_{n}$ is $A=a_{i_{j}}$. When weights $W_{1}, W_{2}, W_{3}, \ldots \ldots W_{n}$ are known, pairwise comparison matrix $A=a_{i_{j}}$ as shown in Equation 1:

$A=\left[a_{i j}\right]=\left[\begin{array}{cccc}W_{1} / W_{1} & W_{1} / W_{2} & \ldots & W_{1} / W_{n} \\ W_{2} / W_{1} & W_{2} / W_{2} & \ldots & W_{2} / W_{n} \\ \cdot & \cdot & \ldots & \cdot \\ W_{n} / W_{1} & W_{n} / W_{2} & \ldots & W_{n} / W_{n}\end{array}\right]$

where, $a_{i j}=W_{i} / W_{j}, a_{j i}=W_{j} / W_{i}, i, j=1,2, \ldots \ldots, \mathrm{n}$

Acquisition of Maximum Eigen Vector and Eigenvalue

According to the pairwise comparison matrix, we obtain the eigen vector and weight distribution of the maximum eigenvalue. Vector $\bar{W}$ of pairwise comparison matrix $\mathrm{A}$ is multiplied by the weights of the criteria, as shown by Equation 2:

$$
\begin{aligned}
& \bar{W}=\left(W_{1}, W_{2}, W_{3}, \ldots \ldots . W_{n}\right)^{T} \\
& {\left[\begin{array}{cccc}
W_{1} / W_{1} & W_{1} / W_{2} & \ldots & W_{1} / W_{n} \\
W_{2} / W_{1} & W_{2} / W_{2} & \ldots & W_{2} / W_{n} \\
\cdot & \cdot & \ldots & \cdot \\
W_{n} / W_{1} & W_{n} / W_{2} & \ldots & W_{n} / W_{n}
\end{array}\right]\left[\begin{array}{c}
W_{1} \\
W_{2} \\
\cdot \\
W_{n}
\end{array}\right]=\lambda\left[\begin{array}{c}
W_{1} \\
W_{2} \\
\cdot \\
W_{n}
\end{array}\right]}
\end{aligned}
$$

According to Equation 2, multiplication between pairwise comparison matrix $\mathrm{A}$ and $\bar{W}$ is equal to that between $\lambda$ and $\bar{W} ; A \bar{W}=\lambda \bar{W}$. Where $\lambda$ is the eigenvalue of $A$ and it is the eigen vector of pairwise matrix $A$ regarding the eigenvalue.

In pairwise comparison, $a_{i j}$ is obtained by subjective judgment. Thus, it should be different from the actual $W_{i} / W_{j}$ and it becomes $a_{i j} \approx W_{i} / W_{j}$. When $a_{i j}$ is slightly changed, the eigen value will also change. When the eigenvalue is not equal to $\lambda, \lambda$ is still the main eigenvalue and is close to the theoretical weight. Thus, $\lambda_{\max }$ replaces $\lambda$, as shown in Equation 3:

$A \bar{W}=\lambda_{\max } \bar{W}$

The step to obtain maximum eigenvalue $\lambda_{\max }$ is shown, as follows. Pairwise comparison matrix A multiplied by eigen vector $\bar{W}$ will result in new vector $\bar{W}^{\prime}$, as shown in Equation 4 and 5: 


$$
A \bar{W}=\bar{W}^{\prime}
$$

$$
\left[\begin{array}{cccc}
W_{1} / W_{1} & W_{1} / W_{2} & \ldots & W_{1} / W_{n} \\
W_{2} / W_{1} & W_{2} / W_{2} & \ldots & W_{2} / W_{n} \\
\cdot & \cdot & \ldots & \cdot \\
W_{n} / W_{1} & W_{n} / W_{2} & \ldots & W_{n} / W_{n}
\end{array}\right]\left[\begin{array}{c}
W_{1} \\
W_{2} \\
\cdot \\
W_{n}
\end{array}\right]=\left[\begin{array}{c}
W_{1^{\prime}} \\
W_{2^{\prime}} \\
\cdot \\
W_{n^{\prime}}
\end{array}\right]
$$

Each known vector is divided by the original vector. The arithmetic mean of the total values obtained is $\lambda_{\max }$, as shown in Equation 6:

$$
\lambda_{\max }=\frac{1}{n}\left(\frac{W_{1}}{W_{1}}+\frac{W_{2}}{W_{2}}+\ldots .+\frac{W_{n}^{\prime}}{W_{n}}\right)
$$

\section{Consistency Testing}

It is difficult to require the subjects' consistency in pairwise comparison. Thus, consistency test is conducted to obtain the Consistency Index (C.I.) in order to determine whether the pairwise comparison matrix of subjects' responses is a Consistency Matrix. According to the suggestion of Saaty, C.I. $=0$ means total consistency of subjects. C.I. $\leq 0.1$ is an acceptable error. Thus, consistency can be guaranteed, as shown in Equation 7:

\section{Consistency Index (C.I.)}

$$
\text { C.I. }=\frac{\lambda_{\max }-n}{n-1}
$$

\section{Consistency Ratio (C.R.)}

In the Positive Reciprocal Matrix, as developed by a scale of $1-9$, the C.I. of different levels is the Random Index (R.I.) (Saaty, 1990). The ratio between C.I. and R.I. of a matrix with the same level is called C.R. $=$ C.I./R.I. (Consistence Ratio). Saaty suggested that when C.R. $\leq 0.1$, consistency is acceptable.

\section{Research Method}

The research method process is as shown in Fig. 2.

\section{Document Analysis}

Based on literature review (Huang, 2015; Hsiao, 2005; Swift, 1995; Dickson, 1966), this study first confirms the research topic and method and reorganizes key factors to select festival planners in order to establish the hierarchical framework and selection factors. According to this study, the key factors to select festival planners are allocated into four principal criteria: Total planning and feasibility, corporate specialty, reliability and image and service quality; and 25 sub-criteria: Content completeness of proposal, feasibility of proposal, specialty of proposal, rationality of expense estimation and distribution, appropriate marketing planning, fit between planning content and activity goals, project managers' professional capacity, place planning and decoration, control of activity details, activity execution capacity, crisis management capacity, planners' negotiation capacity, resources used and distributed, total image and reputation, corporate scale, past execution result, related agreement performance, operational concept, manpower management, exclusive service team, regular and active information of planning progress, cooperation of service team, personnel for responses of questions, immediate offering of professional knowledge information and contact personnel's interactive quality.

\section{Modified Delphi Method}

The Modified Delphi Method is an expert prediction method and it is a kind of group decision-making. Experts provide professional knowledge, capacity, opinions and experience, which lead to common consensus. They complete questionnaires by paper or e-mail. Thus, they can fully express their opinions through professional literacy and self-cognition in private environments. The response rate of questionnaires will be lowered due to the increase of repeated surveys. Hence, this study repeats the questionnaire 2 times and number of experts is 7 .

\section{Data Analysis}

Questionnaire content is based on quantitative analysis to obtain the mean, Standard Deviation and Mode of factors in order to determine the consistency of experts' opinions and compare the difference of factors, shown as follows.

Examination standard:

- Mode: By figures that appear the most in questionnaire results, we can realize the concentration of experts' opinions

- Mean: By questionnaire results, we can realize the importance of experts' opinions

- Standard Deviation: By questionnaire results, we can realize dispersion of experts' opinions

Selection standard: Data analysis of the first-round questionnaire (Hong, 2000):

- Mean is higher than 3.5 and Standard Deviation is lower than 1: Means that the item "is important and it reaches the first common consensus; however, it should be discussed in the second round of the questionnaire"

- When mean is lower than 3.5 and Standard Deviation is higher than 1 , when mean is lower than 3.5 and Standard Deviation is lower than 1, or when mean is higher than 3.5 and Standard Deviation is higher than 1: Means the item "is not important and they do not reach common consensus". It will be eliminated and will not be shown in the second round of the questionnaire 


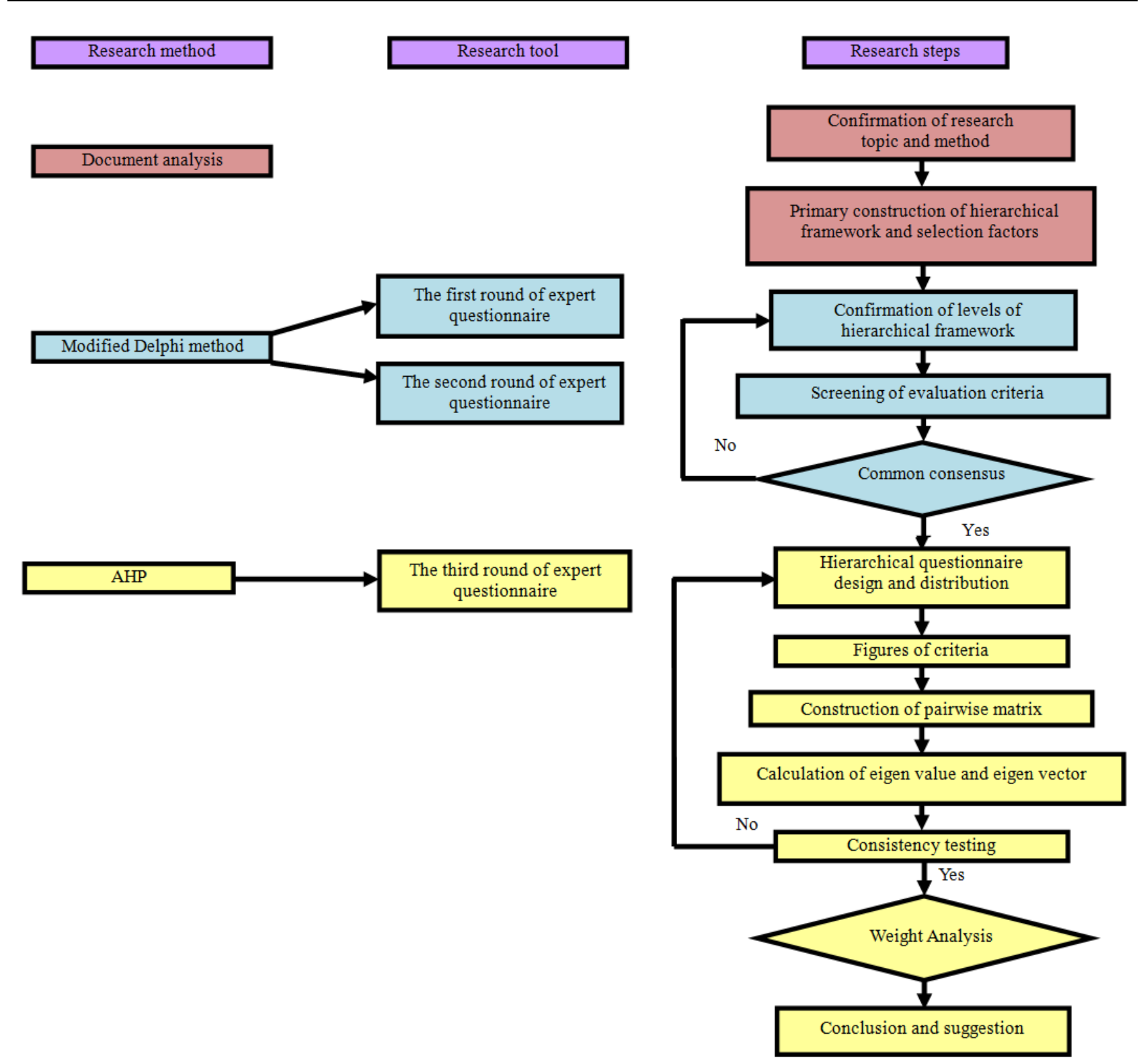

Fig. 2. Research methodology

Data analysis of the second-round questionnaire (Chen, 2011): When mean is higher than 4.0 and Standard Deviation is lower than 1: The item "is important and it reaches common consensus".

\section{AHP}

The hierarchical analysis process of this study is as shown in Fig. 3. The hierarchical structure of selection criteria is as shown in Fig. 4.

\section{Questionnaire Content}

According to the research purpose and framework, this study designs an expert questionnaire to explore the decision-making factors for selecting festival planners and calculate weights of these factors. AHP is used to conducts pairwise comparison of the main factors and compare the importance of two factors. According to Satty's AHP principle, when there are $\mathrm{n}$ factors, there should be $\mathrm{n}(\mathrm{n}-1) / 2$ times of pairwise comparison (Teng and Tzeng, 1989; Satty, 1990).

The questionnaire is based on pairwise comparison; evaluation criteria are at two ends; and the scale is between two criteria. Thus, the decisionmakers evaluate two plans and the expert questionnaire design is as shown in Table 1. 


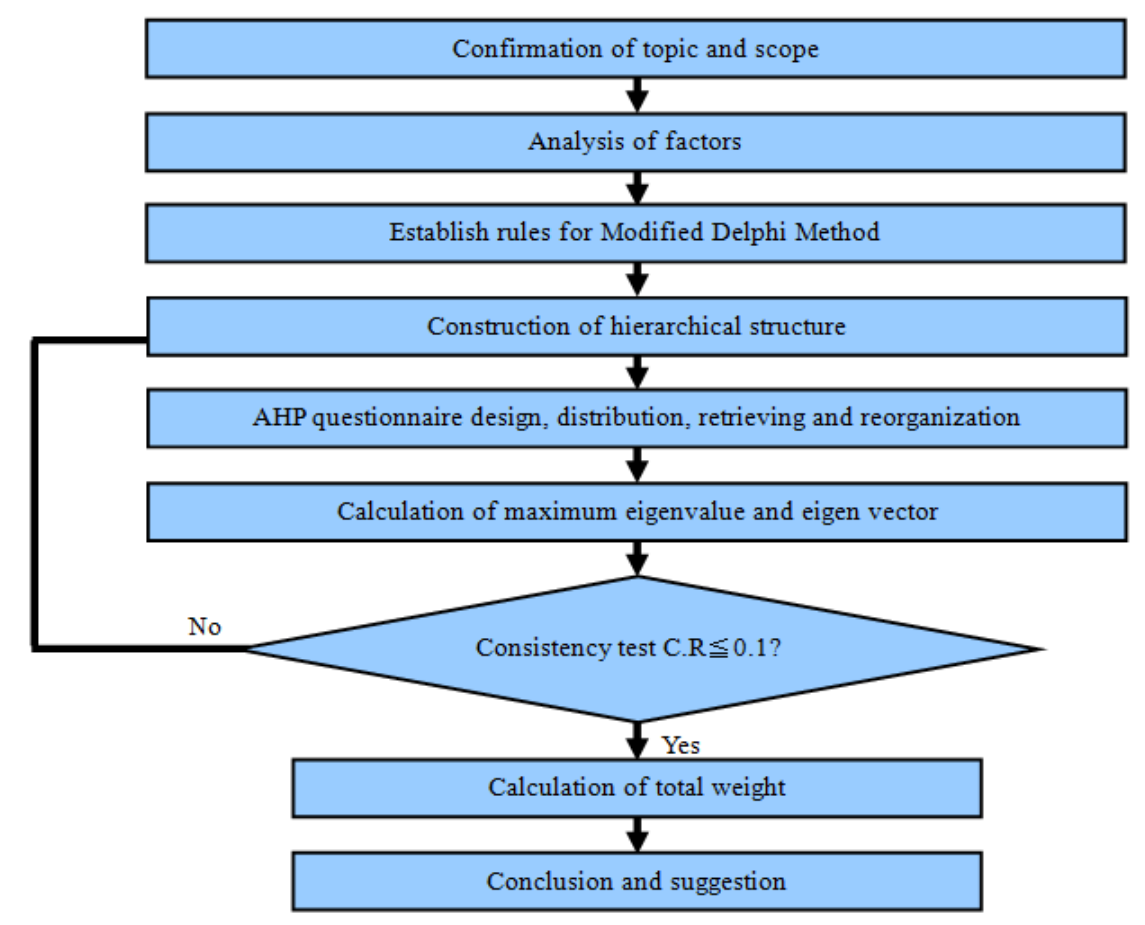

Fig. 3. Process of hierarchical analysis

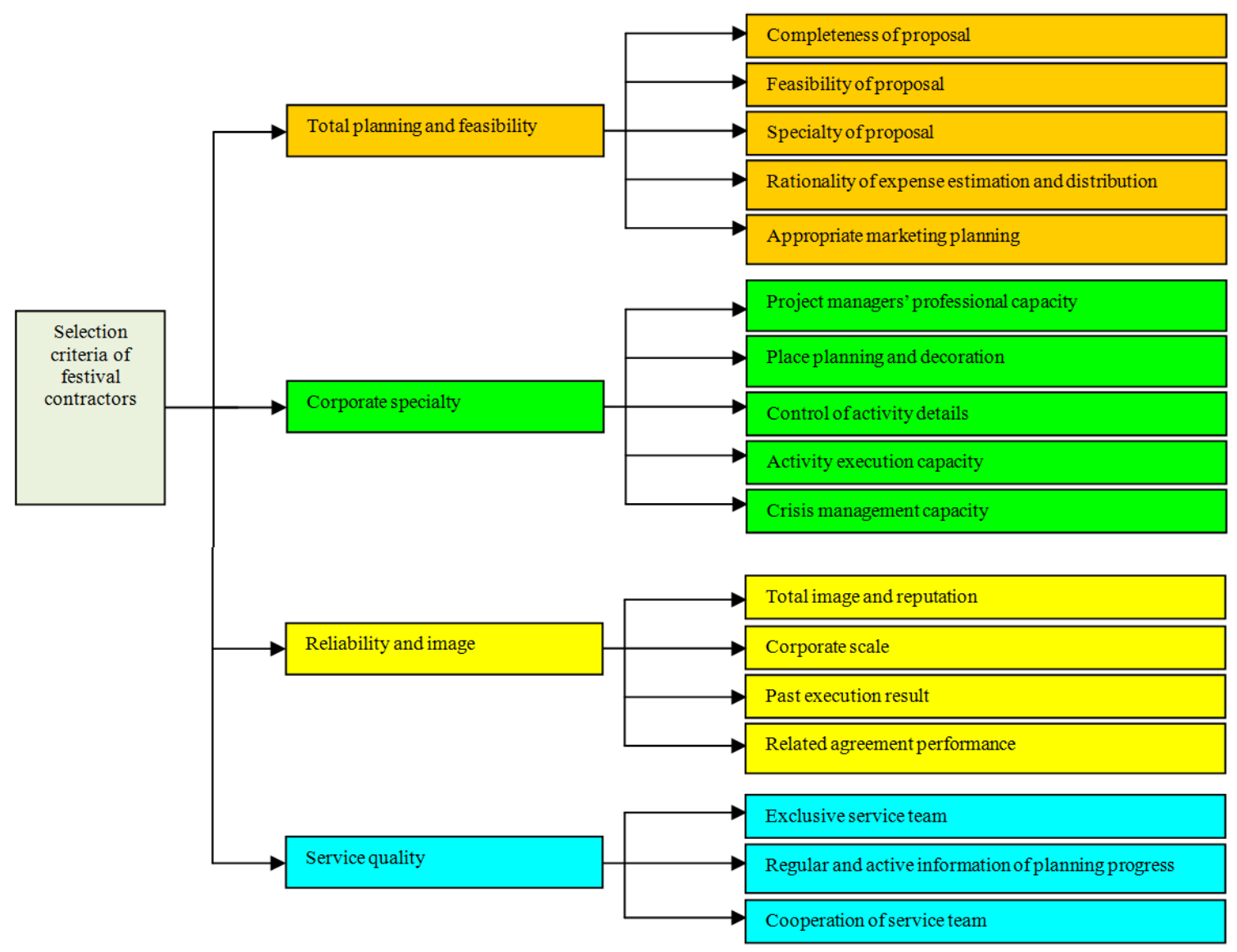

Fig. 4. Hierarchical structure of selection indicators 


\begin{tabular}{|c|c|c|c|c|c|c|c|c|c|c|}
\hline & $\begin{array}{l}\text { Absolutely } \\
\text { important }\end{array}$ & $\begin{array}{l}\text { Extremely } \\
\text { important }\end{array}$ & $\begin{array}{l}\text { Relatively } \\
\text { important }\end{array}$ & $\begin{array}{l}\text { Slightly } \\
\text { important }\end{array}$ & $\begin{array}{l}\text { Equally } \\
\text { important }\end{array}$ & $\begin{array}{l}\text { Slightly } \\
\text { unimportant }\end{array}$ & $\begin{array}{l}\text { Relatively } \\
\text { unimportant }\end{array}$ & $\begin{array}{l}\text { Not } \\
\text { important }\end{array}$ & Unimportant & \\
\hline Criteria & $9: 1$ & $7: 1$ & $5: 1$ & $3: 1$ & $1: 1$ & $1: 3$ & $1: 5$ & $1: 7$ & $1: 9$ & Criteria \\
\hline $\begin{array}{l}\text { Total planning } \\
\text { and feasibility }\end{array}$ & $\mathrm{v}$ & & & & & & & & & $\begin{array}{l}\text { Corporate } \\
\text { specialty }\end{array}$ \\
\hline $\begin{array}{l}\text { Corporate } \\
\text { specialty }\end{array}$ & & $\mathrm{v}$ & & & & & & & & $\begin{array}{l}\text { Reliability } \\
\text { and image }\end{array}$ \\
\hline $\begin{array}{l}\text { Reliability } \\
\text { and image }\end{array}$ & & & & $\mathrm{v}$ & & & & & & $\begin{array}{l}\text { Total planning } \\
\text { and feasibility }\end{array}$ \\
\hline
\end{tabular}

Table 2. Principal criteria and sub-criteria

\begin{tabular}{|c|c|c|}
\hline Goal & Principal criteria & Sub-criteria \\
\hline \multirow[t]{4}{*}{ Selection criteria of festival contractors } & Total planning and feasibility & $\begin{array}{l}\text { Content completeness of proposal } \\
\text { Feasibility of proposal } \\
\text { Specialty of proposal } \\
\text { Rationality of expense estimation and distribution } \\
\text { Appropriate marketing planning }\end{array}$ \\
\hline & Corporate specialty & $\begin{array}{l}\text { Project managers' professional capacity } \\
\text { Place planning and decoration } \\
\text { Control of activity details } \\
\text { Activity execution capacity } \\
\text { Crisis management capacity }\end{array}$ \\
\hline & Reliability and image & $\begin{array}{l}\text { Total image and reputation } \\
\text { Corporate scale } \\
\text { Past execution result } \\
\text { Related agreement performance }\end{array}$ \\
\hline & Service quality & $\begin{array}{l}\text { Exclusive service team } \\
\text { Regular and active information of planning progress } \\
\text { Cooperation of service team }\end{array}$ \\
\hline
\end{tabular}

\section{Results}

\section{Screening Result of Evaluation Criteria}

According to related literature (Huang, 2015; Hsiao, 2005; Swift, 1995; Dickson, 1966), this study reorganizes, studies and establishes the hierarchical framework and evaluation factors and criteria are defined by the Delphi Method. Through experts' two rounds of the Delphi Method questionnaire, criteria are determined. The AHP questionnaire is conducted on experts to decide the relative weights of criteria of different levels. Screening result is as shown in Table 2.

Experts have different positions and views. This study reorganizes experts' opinions and obtains 17 factors, as shown in Table 3.

\section{AHP Result Analysis}

After retrieving the hierarchical analysis questionnaires, this study conducts data analysis by Excel. It first finds the geometric means and weights of pairwise comparisons of different levels, establishes a pairwise comparison matrix to obtain eigen vector and eigenvalue and examines acceptance by consistency testing. Upon the software, the analysis results are shown, as follows.

\section{Result Analysis of Dimensions of Selection Criteria} of Festival Planners

Result analysis of the questionnaire of the four dimensions upon selection indicators of festival planners is shown as follows: (A) total planning and feasibility,
(B) corporate specialty, (C) reliability and image, (D) service quality. Means of dimensions and ranking of weights are as shown in Table 4.

\section{Questionnaire Result Analysis of Criteria}

Analysis of the relative means and factor weight rankings of the four dimensions of selection criteria of festival planners is shown as follows:

- Ranking of dimensions of total planning and feasibility is as follows: (A1) content completeness of proposal, (A2) feasibility of proposal, (A3) specialty of proposal, (A4) rationality of expense estimation and distribution and (A5) appropriate marketing planning, as shown in Table 5

- Ranking of dimensions of corporate specialty is shown as follows: (B1) project managers' professional capacity, (B2) place planning and decoration, (B3) control of activity details, (B4) activity execution capacity and (B5) crisis management capacity, as shown in Table 6

- Ranking of dimensions of reliability and image is shown as follows: (C1) total image and reputation, (C2) corporate scale, (C3) past execution result and (C4) related agreement performance, as shown in Table 7

- Ranking of dimensions of service quality is shown as follows: (D1) exclusive service team, (D2) regular and active information of planning progress, (D3) cooperation of service team, as shown in Table 8 
Table 3. Principal criteria and sub-criteria of selection

Factors

Principal criteria $\begin{array}{ll}\text { Sub-criteria } & \begin{array}{l}\text { Total planning } \\ \text { and feasibility }\end{array}\end{array}$

Service quality

Corporate specialty
Total planning and feasibility

Corporate specialty

Reliability and image

Service quality

Content completeness of proposal

Feasibility of proposal

Specialty of proposal

Rationality of expense

estimation and distribution

Appropriate marketing planning

Project managers' professional capacity

Place planning and decoration

Control of activity details

Activity execution capacity

Crisis management capacity

Reliability and image Total image and reputation

Corporate scale

Past execution result

Related agreement performance

Exclusive service team

Regular and active information

of planning progress

Cooperation of service team
Description

Overall planning and execution of activities

Planners' professional image for external world

Planners' successful experience and positive word-of-mouth

Planners' related services in activity planning

Completeness of the proposal

Feasibility of the reality of the proposal

Professional consultation and planning of proposal according to demand

Appropriate charge of proposal and proper

distribution of different items

Expected promotion effect of the activity

Planners' professional capacity to

deal with and plan the activity

Appropriate selection of location and

decoration to highlight the characteristics

Control of related details of activity in advance

Following of schedule for items planned

Planners' capacity to deal with emergency

Planners' positive image and reputation

Corporate scale that can support the activity

Experience to undertake more

representative and successful activity

Planners' execution according to the content of contract

Professional service team in the activity to enhance efficiency

In the activity, they inform the progress at proper time to

enhance work quality and efficiency

High-degree and precise cooperation with the requirement

Table 4. AHP questionnaire - analysis of dimensions

\begin{tabular}{llllll}
\hline & A & B & C & D & Weight \\
\hline A & 1.000 & 3.115 & 1.761 & 1.932 & 0.414 \\
B & 0.321 & 1.000 & 2.115 & 1.870 & 0.253 \\
C & 0.568 & 0.473 & 1.000 & 1.123 & 0.173 \\
D & 0.518 & 0.535 & 0.890 & 1.000 & 3 \\
\hline
\end{tabular}

Table 5. AHP questionnaire-analysis of dimensions of total planning and feasibility

\begin{tabular}{llllllll}
\hline & A1 & A2 & A3 & A4 & A5 & Weight \\
\hline A1 & 1.000 & 1.728 & 2.395 & 1.446 & 1.623 & 0.294 & 0.283 \\
A2 & 0.579 & 1.000 & 2.274 & 2.713 & 1.801 & 2.052 & 0.171 \\
A3 & 0.417 & 0.440 & 1.000 & 1.000 & 1.777 & 0.143 \\
A4 & 0.691 & 0.369 & 0.555 & 0.563 & 1.000 & 0.109 \\
A5 & 0.616 & 0.387 & 0.487 & & 5 \\
\hline
\end{tabular}

Table 6. AHP questionnaire-analysis of dimensions of corporate specialty

\begin{tabular}{|c|c|c|c|c|c|c|c|}
\hline & B1 & B2 & B3 & B4 & B5 & Weight & Ranking \\
\hline$\overline{\mathrm{B} 1}$ & 1.000 & 4.000 & 3.294 & 2.155 & 2.456 & 0.411 & 1 \\
\hline B2 & 0.250 & 1.000 & 1.801 & 1.236 & 1.255 & 0.167 & 3 \\
\hline B3 & 0.304 & 0.555 & 1.000 & 1.157 & 1.309 & 0.137 & 4 \\
\hline B4 & 0.464 & 0.809 & 0.864 & 1.000 & 2.136 & 0.169 & 2 \\
\hline B5 & 0.407 & 0.797 & 0.764 & 0.468 & 1.000 & 0.116 & 5 \\
\hline
\end{tabular}

Table 7. AHP questionnaire-analysis of dimensions of reliability and image

\begin{tabular}{|c|c|c|c|c|c|c|}
\hline & $\mathrm{C} 1$ & $\mathrm{C} 2$ & C3 & $\mathrm{C} 4$ & Weight & Ranking \\
\hline$\overline{\mathrm{C} 1}$ & 1.000 & 2.295 & 2.030 & 1.464 & 0.384 & 1 \\
\hline $\mathrm{C} 2$ & 0.436 & 1.000 & 1.176 & 0.772 & 0.189 & 4 \\
\hline C3 & 0.493 & 0.851 & 1.000 & 1.314 & 0.209 & 3 \\
\hline C4 & 0.683 & 1.295 & 0.761 & 1.000 & 0.218 & 2 \\
\hline
\end{tabular}

Table 8. AHP questionnaire-analysis of dimensions of service quality

\begin{tabular}{lllll}
\hline & D1 & D2 & D3 & Weight \\
\hline D1 & 1.000 & 3.061 & 1.686 & 0.526 \\
D2 & 0.327 & 1.000 & 1.245 & 0.231 \\
D3 & 0.593 & 0.803 & 1.000 & 3 \\
\hline
\end{tabular}




\begin{tabular}{|c|c|c|c|c|c|c|}
\hline Goal & Principal criteria & Weight & Ranking & Sub-criteria & Weight & Ranking \\
\hline \multirow{17}{*}{$\begin{array}{l}\text { Selection criteria of } \\
\text { festival contractors }\end{array}$} & Total planning & 0.414 & 1 & Content completeness of proposal & 0.294 & 1 \\
\hline & and feasibility & & & Feasibility of proposal & 0.283 & 2 \\
\hline & & & & Specialty of proposal & 0.171 & 3 \\
\hline & & & & Rationality of expense estimation and distribution & 0.143 & 4 \\
\hline & & & & Appropriate marketing planning & 0.109 & 5 \\
\hline & Corporate & 0.253 & 2 & Project managers' professional capacity & 0.411 & 1 \\
\hline & specialty & & & Place planning and decoration & 0.167 & 3 \\
\hline & & & & Control of activity details & 0.137 & 4 \\
\hline & & & & Activity execution capacity & 0.169 & 2 \\
\hline & & & & Crisis management capacity & 0.116 & 5 \\
\hline & Reliability & 0.173 & 3 & Total image and reputation & 0.384 & 1 \\
\hline & and image & & & Corporate scale & 0.189 & 4 \\
\hline & & & & Past execution result & 0.209 & 3 \\
\hline & & & & Related agreement performance & 0.218 & 2 \\
\hline & Service quality & 0.161 & 4 & Exclusive service team & 0.526 & 1 \\
\hline & & & & Regular and active information of planning progress & 0.231 & 3 \\
\hline & & & & Cooperation of service team & 0.243 & 2 \\
\hline
\end{tabular}

Table 10. Analysis of importance of criteria

\begin{tabular}{|c|c|c|c|}
\hline Ranking of weights & Criteria assessment & Weight & Criteria \\
\hline 1 & Content completeness of proposal & 0.12172 & Total planning and feasibility \\
\hline 2 & Feasibility of proposal & 0.11716 & Total planning and feasibility \\
\hline 3 & Project managers' professional capacity & 0.10398 & Corporate specialty \\
\hline 4 & Exclusive service team & 0.08469 & Service quality \\
\hline 5 & Specialty of proposal & 0.07079 & Total planning and feasibility \\
\hline 6 & Total image and reputation & 0.06643 & Reliability and image \\
\hline 7 & Rationality of expense estimation and distribution & 0.05920 & Total planning and feasibility \\
\hline 8 & Appropriate marketing planning & 0.04513 & Total planning and feasibility \\
\hline 9 & Activity execution capacity & 0.04276 & Corporate specialty \\
\hline 10 & Place planning and decoration & 0.04225 & Corporate specialty \\
\hline 11 & Cooperation of service team & 0.03912 & Service quality \\
\hline 12 & Related agreement performance & 0.03771 & Reliability and image \\
\hline 13 & Regular and active information of planning progress & 0.03719 & Service quality \\
\hline 14 & Past execution result & 0.03616 & Reliability and image \\
\hline 15 & Control of activity details & 0.03466 & Corporate specialty \\
\hline 16 & Corporate scale & 0.03270 & Reliability and image \\
\hline 17 & Crisis management capacity & 0.02935 & Corporate specialty \\
\hline
\end{tabular}

Total analysis of the factors is as shown in Table 9. According to the total factors, ranking of weights (from No.1 17) is shown as follows (Table 10): Content completeness of proposal (0.12172), feasibility of proposal (0.11716), project managers' professional capacity (0.10398), exclusive service team (0.08469), specialty of proposal (0.07079), total image and reputation (0.06643), rationality of expense estimation and distribution (0.05920), appropriate marketing planning (0.04513), activity execution capacity (0.04276), place planning and decoration (0.04225), cooperation of service team (0.03912), related agreement performance (0.03771), regular and active information of planning progress $(0.03771)$, past execution result (0.03616), control of activity details $(0.03466)$, corporate scale (0.03270), crisis management capacity (0.02935).

\section{Conclusion}

This study treated the personnel in charge of festivals in firms or departments in northern and central Taiwan as subjects. According to the selection importance of festival planners, whether the planners meet the actual demands is evaluated. Successful organization of festival can bring in economic and promotional benefits and deliver the promotional messages as planned. Marketing, promotion and economic development can all be achieved in festivals.

The tourism industry has great business potential and drives local business development. Festivals can attract visitors and enhance regional development in a short time and are important trends to develop tourism. Around the world, festivals are frequently held to increase the number of visitors, business opportunities and economic benefits. Thus, how to hold successful festivals is an important issue for different countries. The results of this study can serve as reference for selection of festival planners, as well as for promotion of festivals. According to the importance analysis of selection indicators, the ranking weights of evaluation factors are as follows: Content completeness of proposal, feasibility of proposal, project managers' professional capacity, 
exclusive service team, specialty of proposal, total image and reputation, rationality of expense estimation and distribution, appropriate marketing planning, activity execution capacity, place planning and decoration, cooperation of service team, related agreement performance, regular and active information of planning progress, past execution result, control of activity details, corporate scale and crisis management capacity.

\section{Acknowledgement}

This study was developed and planned by Prof. HanChen Huang, Prof. Su-Ling Wu and Prof. Pei-Ying Wu and accomplished with the assistance of Chien-Hua Li. Under the advices of Prof. Su-Ling Wu and Prof. PeiYing $\mathrm{Wu}$, Chien-Hua Li probed into this research topic and tries to obtain the master's degree.

\section{Author's Contributions}

The contribution of all authors is treated equally and there is no conflict of interest among them.

\section{Ethics}

This is an original research work. Ethical issues are not involved here.

\section{References}

Aljuaid, H., Z. Muhammad and M. Sarfraz, 2010. A tool to develop Arabic handwriting recognition system using genetic approach. J. Comput. Sci., 6: 619-624. DOI: 10.3844 /jcssp.2010.619.624

Chang, C.P., 2009. Study on supplier evaluation model: Using service-oriented suppliers in communication industry as examples. Master's Thesis, Institute of Business Management, Ching Yun University, Taiwan.

Chang, H.I., 2013. The evaluation model of employability in tourism industry. Adv. Inform. Sci. Service Sci., 5: 159-168.

Chang, S.H., 2012. Fuzzy multi-criteria evaluation and statistics. Wunan Books, Taipei.

Chen, B.F., 2006. Study on introduction of cultural tourism in assessment on festivals: Using dajia mazu festival as an example. MSc. Thesis, Institute of Land Management, Feng Chia University, Taiwan.

Chen, C.H., 2011. Customer relationship marketing, relationship quality and information technology. Train. Develop. Fashion, 28: 8-12.

Cheng, C.H. and M.C. Liu, 2006. Study on relationship between residents' recreational life style and physical and mental health in Taiwan. National Science Council Project.

Dickson, G.W., 1966. An analysis of vendor selection systems and decisions. J. Purchas., 2: 563-588.
Huang, H.C., 2015. Applying fuzzy analytic hierarchy process to construct a festival planner selection model. Adv. Inform. Sci. Service Sci., 7: 52-61.

Huang, D.S., 2003. Festivals in Taiwan. Yuan-Zu Publishing, Taipei.

Huang, J.Y., 1996. Marketing study: Management and technique. Huatai Books, Taipei.

Hong, D.C., 2000. Risk cognition and management of BOT Finance of Kaohsiung rapid transit corporation: Delphi method and AHP. MSc. Thesis of Department of Financial Operation, National Kaohsiung First University of Science and Technology, Taiwan.

Hsiao, H.F., 2005. Construction of supplier selection decision-making model by fuzzy quality function deployment: Using network communication industry as an example. MSc. Thesis, Department of Information Management, Shih Hsin University, Taiwan.

Lee, Y., C. Lee, S. Lee and B.J. Babin, 2008. Festivalscapes and patrons' emotions, satisfaction and loyalty. J. Bus. Res., 61: 56-64. DOI: 10.1016/j.jbusres.2006.05.009

Liu, C.J., Y.H. Liu and H.R. Meng, 2008. Study on construction of participants' cognitive model on local festival benefits in Taiwan. Hum. Social Sci. Res., 2: 141-162.

Liu, Y.L. and Y.L. Shih, 2009. Study on correlation among attraction, tourist satisfaction and revisit intention of dragon boat festival in Lukang. J. Leisure Recreat. Industry Manage., 2: 28-49.

Ma, H., Y. Cao and N. Cai, 2014. On evaluation of index system of new socialist countryside in ethnic regions of China: An AHP-based fuzzy approach. Int. J. Soft Comput. Applic., 2: 1-7.

Murry, J.W. and J.O. Hammons, 1995. Delphi: A versatile methodology for conducting qualitative research. Rev. Higher Educ., 4: 423-436.

Quinn, B., 2003. Symbols, practices and myth-making: Cultural perspectives on the Wexford festival opera. Tourism Geographies, 5: 329-349. DOI: $10.1080 / 14616680309710$

Saaty, T.L., 1990. How to make a decision: The analytic hierarchy process. Eur. J. Operat. Res., 48: 9-26. DOI: 10.1016/0377-2217(90)90057-I

Swift, C.O., 1995. Preferences for single sourcing and supplier selection criteria. J. Bus. Res., 32: 105-111. DOI: 10.1016/0148-2963(94)00043-E

Teng, J.Y. and G.H. Tzeng, 1989. Content characteristics and application of Analytic Hierarchy Process (AHP) (I). J. Chinese Statist. Associat., 27: 6-22.

Wang, Y.Q., 1999. Folk activities and festivals, creation of new tourism resources. Yang Chi Culture, Taipei. 